\title{
Increased antioxidant capacity in the plasma of dogs after a single oral dosage of tocotrienols
}

\author{
Jens Raila $^{1 *}$, Sascha Rohn ${ }^{2}$, Florian J. Schweigert ${ }^{1}$ and Getu Abraham ${ }^{3}$ \\ ${ }^{1}$ Institute of Nutritional Science, University of Potsdam, Arthur-Scheunert-Allee 114-116, D-14558 Nuthetal, Germany \\ ${ }^{2}$ Institute of Food Chemistry, University of Hamburg, Grindelallee 117, D-20146 Hamburg, Germany \\ ${ }^{3}$ Faculty of Veterinary Medicine, Institute of Pharmacology, Pharmacy and Toxicology, University of Leipzig, \\ An den Tierkliniken 15, D-04103 Leipzig, Germany
}

(Received 15 October 2010 - Revised 27 November 2010 - Accepted 11 January 2011)

\section{Abstract}

The intestinal absorption of tocotrienols (TCT) in dogs is, to our knowledge, so far unknown. Adult Beagle dogs $(n$ 8) were administered a single oral dosage of a TCT-rich fraction (TRF; $40 \mathrm{mg} / \mathrm{kg}$ body weight) containing $32 \% \alpha$-TCT, $2 \% \quad \beta$-TCT, $27 \% \gamma$-TCT, $14 \% \delta$-TCT and $25 \% \alpha$-tocopherol ( $\alpha$-TCP). Blood was sampled at baseline (fasted), 1, 2, 3, 4, 5, 6, 8 and $12 \mathrm{~h}$ after supplementation. Plasma and chylomicron concentrations of TCT and $\alpha$-TCP were measured at each time point. Plasma TAG were measured enzymatically, and plasma antioxidant capacity was assessed by the Trolox equivalent antioxidant capacity assay. In fasted dogs, levels of TCT were $0 \cdot 07$ (SD 0.03$) \mu \mathrm{mol} / 1$. Following the administration of the TRF, total plasma TCT peaked at $2 \mathrm{~h}(7 \cdot 16$ (SD $3 \cdot 88) \mu \mathrm{mol} / \mathrm{l} ; P<0 \cdot 01)$ and remained above baseline levels $(0.67(\mathrm{SD} 0.44) \mu \mathrm{mol} / 1 ; P<0.01)$ at $12 \mathrm{~h}$. The TCT response in chylomicrons paralleled the increase in TCT in plasma with a maximum peak $(3.49$ (SD 2.06$) \mu \mathrm{mol} / \mathrm{l} ; P<0.01$ ) at $2 \mathrm{~h}$ post-dosage. $\alpha$-TCP was the major vitamin $\mathrm{E}$ detected in plasma and unaffected by TRF supplementation. The Trolox equivalent values increased from $2 \mathrm{~h}$ (776 (SD $51 \cdot 2$ ) $\mu$ mol/1) to a maximum at $12 \mathrm{~h}$ (1130 (sD 7.72) $\mu \mathrm{mol} / 1 ; P<0.01$ ). The results show that TCT are detected in postprandial plasma of dogs. The increase in antioxidant capacity suggests a potential beneficial role of TCT supplementation in the prevention or treatment of several diseases in dogs.

\section{Key words: Dogs: Tocotrienols: Intestinal absorption: Antioxidant capacity}

Vitamin $\mathrm{E}$ is a potent lipid-soluble antioxidant that is only synthesised by plants and cyanobacteria, and therefore it is essential for human and animal nutrition ${ }^{(1)}$. In nature, compounds with vitamin $\mathrm{E}$ activity include $\alpha-, \beta-, \gamma$ - and $\delta$-tocopherols (TCP) as well as $\alpha-, \beta-, \gamma$ - and $\delta$-tocotrienols (TCT). The molecular structure of TCT differs from the corresponding TCP in their aliphatic tail containing an unsaturated isoprenoid chain, whereas the tail of TCP has a saturated phytyl chain ${ }^{(1)}$. TCT are minor plant constituents especially abundant in palm oil, cereal grains and rice bran, all providing significant sources of vitamin $\mathrm{E}$ activity ${ }^{(2)}$. The antioxidant properties of TCT have been well investigated by several in vitro experiments and seem to be higher than those of $\alpha-\mathrm{TCP}^{(3,4)}$. Recently, TCT have gained increasing scientific interest mainly by the discovery of their non-antioxidant actions, which include neuroprotective, anti-carcinogenic and cholesterol-lowering properties ${ }^{(5,6)}$. These properties of TCT have also spurred interest in determining their ability to prevent degenerative diseases ${ }^{(7)}$. However, TCT metabolism in dogs or other companion animals is not known. Therefore, the present study was conducted to measure the intestinal absorption of TCT and antioxidant capacity in the plasma of dogs receiving a single oral dosage of TCT.

\section{Experimental methods}

\section{Animals and experimental design}

A total of eight adult Beagle dogs, age ranging from 3 to 6 years (average 3.8 years), were enrolled in the present study according to the guidelines for animal welfare of the German Society of Experimental Animal Science. The study protocol was approved by the local Animal Welfare Committee (Referat 74; Regierungspräsidium, Leipzig, Germany). Dogs were fed a commercial dry dog food (Altromin breeding and maintenace diet for dogs \#4130; Altromin Spezialfutter $\mathrm{GmbH}$, Lage, Germany) formulated to meet the nutrient recommendations of the National Research Council for adult dogs ${ }^{(8)}$. Crude nutrient and energy content of the basal diet per $\mathrm{kg}$ were as follows: DM (880 g); crude protein $(240 \mathrm{~g})$;

Abbreviations: TCP, tocopherols; TCT, tocotrienols; TRF, tocotrienol-rich fraction; TTP, tocopherol transfer protein. 
crude fat $(55 \mathrm{~g})$; crude fibre $(40 \mathrm{~g})$; crude ash $(95 \mathrm{~g})$; $\mathrm{N}$-free extract (450 g); metabolisable energy (12.5 MJ); Ca (14g); $\mathrm{P}(11 \mathrm{~g}) ; \mathrm{Mg}(2 \mathrm{~g})$; Na (2 g); K (9g); vitamin A (4500 $\mu \mathrm{g}$ retinol equivalents); vitamin $\mathrm{D}_{3}(15 \mu \mathrm{g})$; vitamin $\mathrm{E}$ (as $\alpha$-tocopherol acetate, $75 \mathrm{mg}$ ). Dogs had free access to tap water. Following an overnight fast, the animals received an oral bolus of $40 \mathrm{mg} / \mathrm{kg}$ body weight of a tocotrienol-rich fraction (TRF) extracted from palm oil (Gold Tri E; Golden Hope Plantations Berhard, Kuala Lumpur, Malaysia) containing 32\% $\alpha$-TCT, $2 \%$ $\beta$-TCT, $27 \% \gamma$-TCT, $14 \% \delta$-TCT and $25 \% \alpha$-TCP, together with $5 \mathrm{ml}$ cream (fat, $30 \% ; \alpha$-TCP, $0.9 \mu \mathrm{g} / \mathrm{ml}$ ). A baseline blood sample was collected from the cephalic vein into EDTA-evacuated tubes immediately before administration of the TRF, and subsequent serial blood samples were collected at $1,2,3,4,5,6,8$ and $12 \mathrm{~h}$ post-dosage.

\section{Analytical methods}

Plasma was prepared by centrifugation of the blood samples ( $1500 \mathrm{~g} ; 10 \mathrm{~min}$ at $4^{\circ} \mathrm{C}$ ), and the chylomicrons were isolated by ultracentrifugation $\left(30 \mathrm{~min}, 100000 \mathrm{~g}\right.$ at $10^{\circ} \mathrm{C}$ ) from $1 \mathrm{ml}$ fresh plasma at density $<1.006 \mathrm{~g} / \mathrm{ml}^{(9)}$. Plasma and chylomicrons were organically extracted with $n$-hexane stabilised with $0.05 \%$ butylated hydroxytoluene for measuring their TCT and $\alpha$-TCP concentrations, and were separated using a modified gradient RP-HPLC system (Waters, Eschborn, Germany) with a C30 column $(5 \mu \mathrm{m}, \quad 250 \times 4.6 \mathrm{~mm}$; YMC, Wilmington, NC, USA) as described elsewhere ${ }^{(10)} \cdot \alpha-$, $\beta-, \gamma-$ and $\delta$-TCT and $\alpha$-TCP were identified by comparing the retention time and the peak area with external standards (BASF, Ludwigshafen, Germany) using a Waters 474 fluorescence detector (excitation $290 \mathrm{~nm}$, emission $330 \mathrm{~nm}$ ). All solvents or chemicals used for extraction or HPLC were of high-purity commercial grade (Roth, Karlsruhe, Germany). Plasma TAG concentrations were measured using a commercially available enzymatic colorimetric assay kit (Thermo Electron, Melbourne, VIC, Australia). The total antioxidant status in plasma was determined by the Trolox equivalent antioxidant capacity assay as described elsewhere ${ }^{(11)}$.

\section{Statistical analysis}

Results are expressed as means and standard deviations. Variations in the response variable were partitioned using the general linear model procedure of SPSS (version 15.0; SPSS Inc., Chicago, IL, USA) for repeated-measures design. The maximum plasma concentration and the time to reach maximum plasma concentration were obtained directly from the plasma values. Statistical significance was accepted at $P<0.05$.

\section{Results}

Male dogs ( $n$ 4) weighed 14.3 (SD 1.06) kg and female dogs ( $n$ 4) weighed 12.7 (SD 1.33$) \mathrm{kg}$. Total plasma TCT concentrations (sum of $\alpha-, \beta-, \gamma$ - and $\delta$-TCT) at baseline $(0 \mathrm{~h})$ were only detectable in three out of eight dogs and gave a mean value of $0.07(\mathrm{SD} 0.03) \mu \mathrm{mol} / \mathrm{l}$. As a consequence of the administration of $40 \mathrm{mg} \mathrm{TRF} / \mathrm{kg}$ body weight, plasma total TCT concentrations peaked at $2 \mathrm{~h}$ and reached the highest values $(P<0.01)$ ranging between 5.69 and $18.11 \mu \mathrm{mol} / \mathrm{l}$ (Fig. 1(a)). At this time point, $\alpha$-TCT (43 (SD 12)\%) as well as $\beta$ - and $\gamma$-TCT (43 (SD 7)\%) were the predominant form of TCT followed by $\delta$-TCT (13.3 (SD 6.35)\%). Starting from $2 \mathrm{~h}$ and beyond, plasma TCT content was significantly higher $(P<0 \cdot 01)$ than the baseline levels throughout the postprandial intervention, and at $12 \mathrm{~h}$ post-TRF dosage, total TCT levels were still significantly higher than the baseline levels $(0.67$ (sD 0.44$) \mu \mathrm{mol} / 1 ; P<0 \cdot 01$ ). Plasma $\alpha$-TCP was the major circulating vitamin $\mathrm{E}$ isomer at baseline (128 (SD 21.3) $\mu \mathrm{mol} / \mathrm{l})$ and remained constant during the entire $12 \mathrm{~h}$ study interval. The total TCT response in the chylomicrons (Fig. 1(b)) paralleled the increase in TCT observed in plasma with a peak at $2 \mathrm{~h}$ (3.49 (SD 2.06) $\mu \mathrm{mol} / 1 ; P<0.01$ ) and was accompanied with the maximum increment in plasma TAG (Fig. 1(c)). The total antioxidant capacity in plasma measured as Trolox equivalents (Fig. 1(d)) increased continuously from $2 \mathrm{~h}$ post-TRF dosage (776 (SD 51.2) $\mu \mathrm{mol} / \mathrm{l}$ ) to maximum concentrations at $12 \mathrm{~h}$ (1130 (sD 77.2) $\mu \mathrm{mol} / \mathrm{l})(P<0 \cdot 01)$.

\section{Discussion}

To our knowledge, the present results demonstrate for the first time that dogs are capable of absorbing orally ingested TCT from a TRF obtained from palm oil as the plasma and chylomicron $\alpha$-, $\beta$-, $\gamma$ - and $\delta$-TCT levels increased throughout the postprandial period. The maximum increment in TCT concentrations in plasma and chylomicrons was paralleled by peaked TAG, suggesting that intestinal TCT absorption in dogs is processed similarly as other dietary lipids, although no direct evidence is available. Moreover, the distribution of the TCT isomers at the time of their maximal plasma concentrations reflects the percentage distribution of TCT in the palm oil TRF supplement. This result suggests that in dogs, the intestinal absorption rate is not different among $\alpha-, \beta-, \gamma$ - and $\delta$-TCT, which seems to be the same situation as in human subjects ${ }^{(12-14)}$, but it is in contrast to rats, in which $\alpha$-TCT is absorbed preferentially compared with $\gamma$ - and $\delta$-TCT ${ }^{(15,16)}$.

In the present study, $\alpha$-TCP was the major vitamin $\mathrm{E}$ isomer in plasma, even when dogs were challenged with a preparation whose composition was high $(75 \%)$ in TCT. This finding is in agreement with previous studies that examined the effect of TCT supplementation in human subjects ${ }^{(12,14,17)}$ and might be due to a rapid replacement of $\alpha$-TCP in plasma lipoproteins by newly absorbed $\alpha$-TCP from the gut ${ }^{(18)}$. Thus, it was concluded that the capacity to increase plasma $\alpha$-TCP concentrations is limited ${ }^{(19)}$. Moreover, it is well established that intestinal chylomicrons are converted to remnant particles that are subsequently taken up by the liver, where newly absorbed vitamin $\mathrm{E}$ is incorporated into nascent VLDL ${ }^{(20)}$. Of the various isomers of dietary vitamin E, $\alpha$-TCP is preferentially secreted by the liver into the plasma VLDL mediated by $\alpha$-tocopherol transfer protein (TTP) ${ }^{(20,21)}$. By contrast, the transfer of TCT into VLDL may be independent of TTP function, because TTP has a comparatively poor efficiency to transport TCT than $\alpha$-TCP ${ }^{(22)}$. On the other hand, feeding experiments in rats have shown that oral TCT not only 
(a)

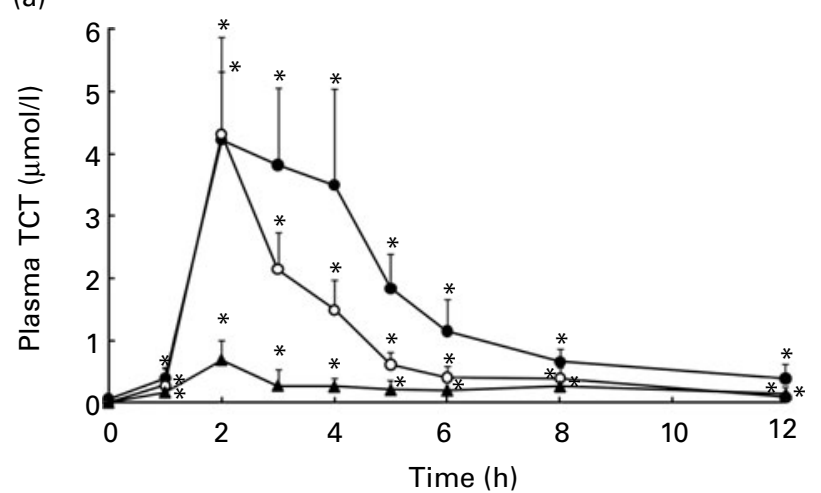

(c)

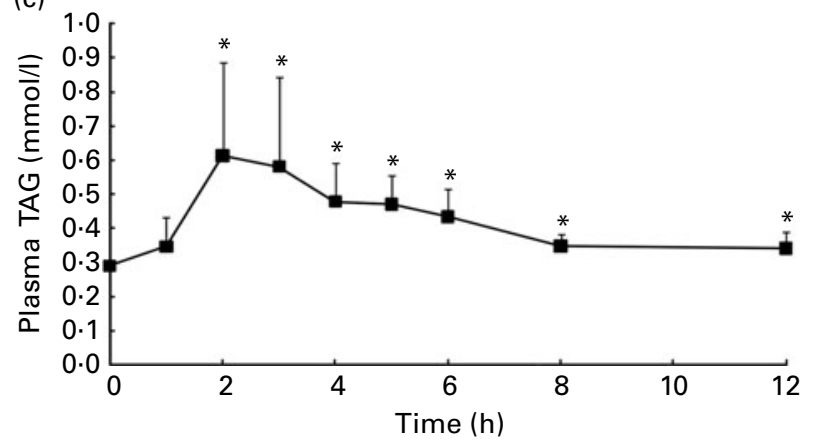

(b)

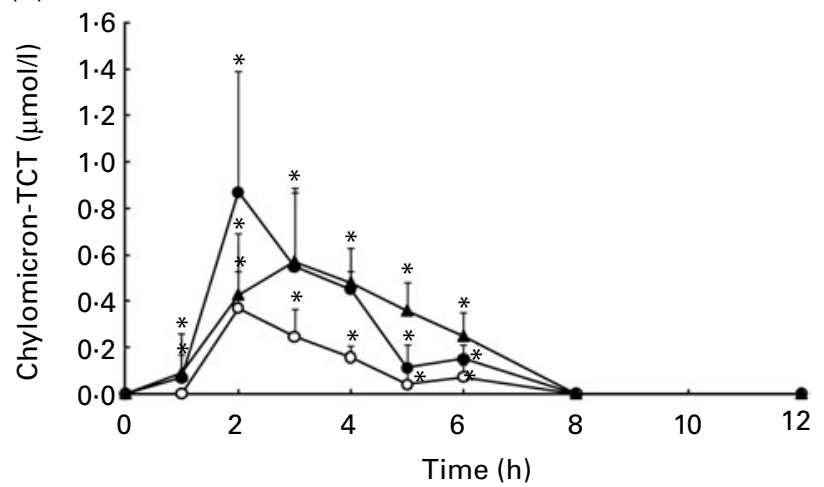

(d)

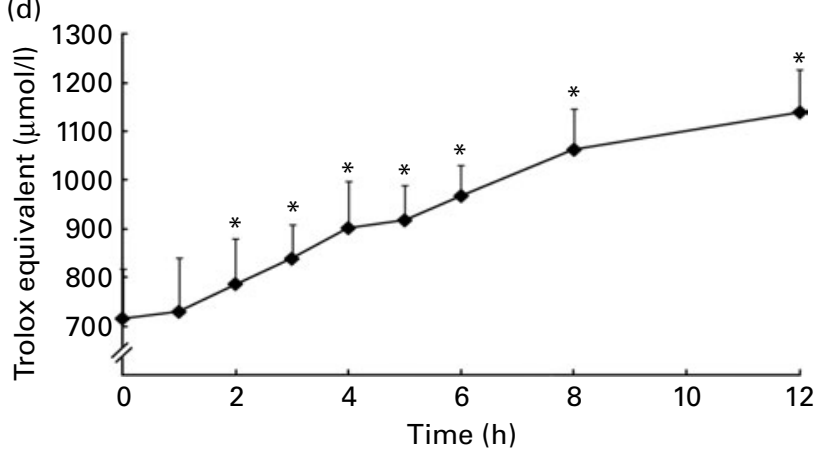

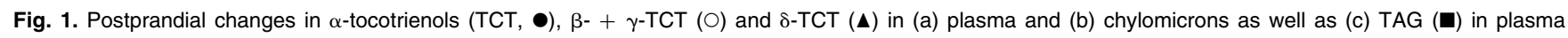
and (d) Trolox equivalents ( $\bullet$ ) in the plasma of eight dogs measured after the intake of a tocotrienol-rich fraction ( $40 \mathrm{mg} / \mathrm{kg}$ body weight). Values are means, with standard deviations represented by vertical bars. *Mean values were significantly higher relative to the baseline levels on the basis of the general linear model procedure of SPSS $(t=0 ; P<0.05)$.

reach the plasma but also accumulate in considerable amounts in several tissues including the heart, lung and skin ${ }^{(23)}$. In addition, a long-term feeding trial has demonstrated that dietary $\alpha$-TCT can be detected in plasma and all tissues of rats fed a diet containing $\alpha$-TCT for 8 weeks ${ }^{(24)}$. Thus, it is at present not clear whether, or to what extent, the delivery of orally supplemented TCT to peripheral tissues is dependent on the function of $\mathrm{TTP}^{(6)}$. Another explanation of the lower affinity of TCT for $\alpha$-TTP is the rapid degradation of TCT to water-soluble carboxychromans and subsequent excretion into urine ${ }^{(25)} . \beta$ - and $\gamma$-TCT rather than $\alpha$-TCT may be preferentially metabolised ${ }^{(26)}$, which would explain the more rapid decline in plasma $\beta$ - and $\gamma$-TCT concentrations in the present study.

All vitamin $\mathrm{E}$ isomers are well known for their antioxidant properties $^{(6)}$. Structurally, TCT differ from TCP by the presence of the unsaturated isoprenoid side chain and are thought to be more potent antioxidants than $\alpha-\mathrm{TCP}^{(3,4)}$. The antioxidant ability of TCT and TCP was mainly investigated in several in vitro experiments ${ }^{(21)}$. In the present study, the total plasma antioxidant capacity was measured in vivo and a continuous increase in Trolox equivalents throughout the postprandial intervention was found, while the concentrations of total TCT already peaked at $2 \mathrm{~h}$ post-dosage. This result seems to contradict with the assumption that TCT are able to enhance plasma antioxidant capacity. However, with the data obtained in the present study, it is difficult to address the mechanism of the antioxidant action of TCT in vivo, because the transport and exchange of TCT among lipoproteins, the presence of carrier proteins specific for TCT and especially the incorporation of TCT into the target cells remain unknown in dogs. Moreover, TCT are able to activate the nuclear pregnane $\mathrm{X}$ receptor and thus regulate the expression of several target genes that are involved in the antioxidant defence system including glutathione $S$-transferase ${ }^{(27)}$. The delayed activity of such antioxidant-active enzymes may be an explanation for the observed time differences between the maximum TCT and Trolox equivalent concentrations in the plasma of dogs.

In summary, the present results show that dogs are able to absorb $\alpha-, \beta-, \gamma$ - and $\delta$-TCT isomers after the oral administration of a TRF obtained from palm oil. This result and the observed increase in total plasma antioxidant capacity provide significant information regarding the biopotency of TCT isomers in dogs. The supplementation with TCT may therefore be considered in the prevention and treatment of several degenerative diseases that are accompanied with increased oxidative stress.

\section{Acknowledgements}

The present study received no specific grant from any funding agency in the public, commercial or not-for-profit sectors. All authors contributed to the conception and design of the study, the acquisition and interpretation of the data and writing of the manuscript. There is no conflict of interest for any of the authors. 


\section{References}

1. Schneider C (2005) Chemistry and biology of vitamin E. Mol Nutr Food Res 49, 7-30.

2. Ong AS (1993) Natural sources of tocorienols. In Vitamin E in Health and Disease, pp. 3-8 [L Packer and J Fuchs, editors]. New York/Basel/Hong Kong: Marcel Dekker, Inc.

3. Serbinova E, Kagan V, Han D, et al. (1991) Free radical recycling and intramembrane mobility in the antioxidant properties of alpha-tocopherol and alpha-tocotrienol. Free Radic Biol Med 10, 263-275.

4. Begum AN \& TeraoJ (2002) Protective effect of alpha-tocotrienol against free radical-induced impairment of erythrocyte deformability. Biosci Biotechnol Biochem 66, 398-403.

5. Packer L, Weber SU \& Rimbach G (2001) Molecular aspects of alpha-tocotrienol antioxidant action and cell signalling. J Nutr 131, 369S-373S.

6. Sen CK, Khanna S \& Roy S (2007) Tocotrienols in health and disease: the other half of the natural vitamin E family. Mol Aspects Med 28, 692-728.

7. Theriault A, Chao JT, Wang Q, et al. (1999) Tocotrienol: a review of its therapeutic potential. Clin Biochem 32, $309-319$.

8. NRC (2006) Requirements of Dogs and Cats. Washington, DC: National Academy Press.

9. Havel R, Eder H \& Bragdon J (1955) The distribution and chemical composition of ultracentrifugally separated lipoproteins in human serum. J Clin Invest 34, 1345-1353.

10. Raila J, Willnow TE \& Schweigert FJ (2005) Megalinmediated reuptake of retinol in the kidneys of mice is essential for vitamin A homeostasis. J Nutr 135, 2512-2516.

11. Carlsohn A, Rohn S, Bittmann F, et al. (2008) Exercise increases the plasma antioxidant capacity of adolescent athletes. Ann Nutr Metab 53, 96-103.

12. O'Byrne D, Grundy S, Packer L, et al. (2000) Studies of LDL oxidation following alpha-, gamma-, or delta-tocotrienyl acetate supplementation of hypercholesterolemic humans. Free Radic Biol Med 29, 834-845.

13. Yap SP, Yuen KH \& Wong JW (2001) Pharmacokinetics and bioavailability of alpha-, gamma- and delta-tocotrienols under different food status. J Pharm Pharmacol 53, 67-71.

14. Fairus S, Nor RM, Cheng HM, et al. (2006) Postprandial metabolic fate of tocotrienol-rich vitamin $\mathrm{E}$ differs significantly from that of alpha-tocopherol. Am J Clin Nutr 84, 835-842.
15. Ikeda I, Imasato Y, Sasaki E, et al. (1996) Lymphatic transport of alpha-, gamma- and delta-tocotrienols and alpha-tocopherol in rats. Int J Vitam Nutr Res 66, 217-221.

16. Yap SP, Yuen $\mathrm{KH} \& \operatorname{Lim} \mathrm{AB}$ (2003) Influence of route of administration on the absorption and disposition of alpha-, gamma- and delta-tocotrienols in rats. $J$ Pharm Pharmacol 55, 53-58.

17. Mensink RP, van Houwelingen AC, Kromhout D, et al. (1999) A vitamin E concentrate rich in tocotrienols had no effect on serum lipids, lipoproteins, or platelet function in men with mildly elevated serum lipid concentrations. Am J Clin Nutr 69, 213-219.

18. Traber MG, Rader D, Acuff RV, et al. (1998) Vitamin E dose-response studies in humans with use of deuterated RRR-alpha-tocopherol. Am J Clin Nutr 68, 847-853.

19. Brigelius-Flohe R, Kelly FJ, Salonen JT, et al. (2002) The European perspective on vitamin E: current knowledge and future research. Am J Clin Nutr 76, 703-716.

20. Traber MG, Burton GW \& Hamilton RL (2004) Vitamin E trafficking. Ann N Y Acad Sci 1031, 1-12.

21. Schaffer S, Muller WE \& Eckert GP (2005) Tocotrienols: constitutional effects in aging and disease. J Nutr 135, 151-154.

22. Hosomi A, Arita M, Sato Y, et al. (1997) Affinity for alphatocopherol transfer protein as a determinant of the biological activities of vitamin E analogs. FEBS Lett 409, 105-108.

23. Khanna S, Patel V, Rink C, et al. (2005) Delivery of orally supplemented alpha-tocotrienol to vital organs of rats and tocopherol-transport protein deficient mice. Free Radic Biol Med 39, 1310-1319.

24. Ikeda S, Tohyama T, Yoshimura H, et al. (2003) Dietary alpha-tocopherol decreases alpha-tocotrienol but not gamma-tocotrienol concentration in rats. $J$ Nutr $\mathbf{1 3 3}$, 428-434.

25. Brigelius-Flohe R (2003) Vitamin E and drug metabolism. Biochem Biophys Res Commun 305, 737-740.

26. Birringer M, Pfluger P, Kluth D, et al. (2002) Identities and differences in the metabolism of tocotrienols and tocopherols in HepG2 cells. J Nutr 132, 3113-3118.

27. Landes N, Pfluger P, Kluth D, et al. (2003) Vitamin E activates gene expression via the pregnane $\mathrm{X}$ receptor. Biochem Pharmacol 65, 269-273. 